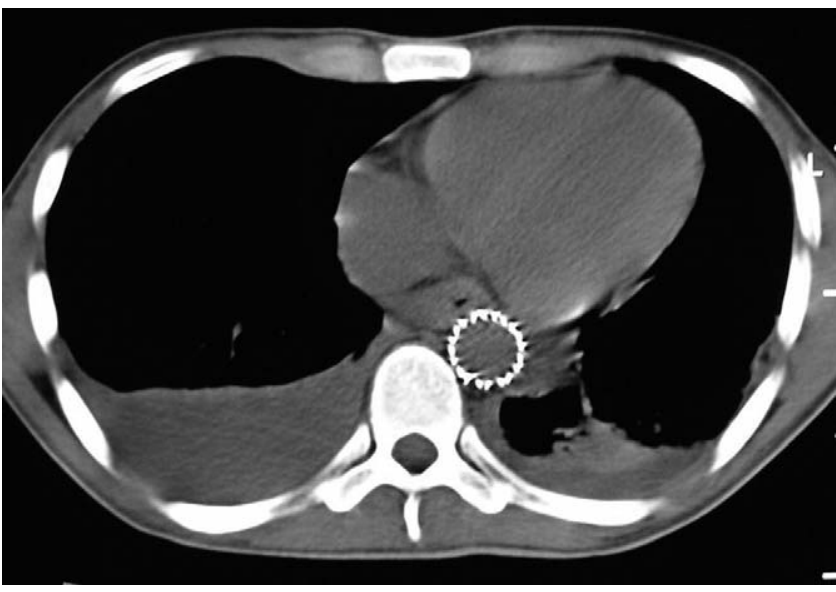

Figure 2. Postoperative computed tomographic scan showing correct positioning of the endoprosthesis and reduction in inflammation of mediastinal fat tissue.

cases of aortoesophageal fistula caused by corrosive ingestion are reported in the literature.

In cases of surgically repaired aortoesophageal fistulas reported in the literature, ${ }^{2,3}$ suture or prosthetic graft replacement of the aorta did not prove to be an adequate treatment because death from secondary hemorrhage often occurred because of late dehiscence and reopening of the aortic breach. The first case of aortoesophageal fistula repair with an endovascular stent graft was reported by Kato and associates ${ }^{4}$ in 2000. In this case the fistula was caused by irradiation of an esophageal cancer, and therefore intervention was palliative. In our case the aim was a definitive and minimally invasive treatment in a critically ill young man with impending coagulopathy. Endovascular treatment after primary repair of the laceration in the esophagus and in the aorta and after extensive debridement was the only way to definitively treat this condition while avoiding further surgical stress to the patient. In our case the infective risk for the endoprosthesis was minimal because of preoperative broad-spectrum antibiotic therapy and deployment of the graft inside an intact aortic wall. Successful surgical treatment of aortoesophageal fistulas caused by corrosive injury is rarely reported in the literature, and no cases of endovascular repair of this condition have been reported. Because surgical treatment alone is not able to result in a definitive solution, endovascular repair of the fistula and strengthening of malacic aortic walls by means of a stent graft can be a life-saving and successful approach. Further experience and follow-up will eventually confirm this result.

\section{References}

1. Maher MM, Murphy J, Dervan P, O'Connell D. Aorto-oesophageal fistula presenting as a submucosal oesophageal haematoma. $\mathrm{Br}$ J Radiol. 1998;71:972-4.

2. Lim CC, Cheah FK, Tan JC. Spiral computed tomography demonstration of aorto-oesophageal fistula from fish-bone. Clin Radiol. 2000;55: 976-7.

3. Reddi A, Chetty R. Primary aorto-esophageal fistula due to Takayasu's aortitis. Cardiovasc Pathol. 2003;12:112-4.

4. Kato N, Tadanori H, Tanaka K, Yasuda F, Iwata M, Kawarada Y, et al. Aortoesophageal fistula-relief of massive hematemesis with an endovascular stent-graft. Eur J Radiol. 2000;34:63-6.

\title{
Surgical treatment of pulmonary artery sarcoma
}

Neal C. Chhaya, MRCS, ${ }^{a}$ Andrew T. Goodwin, FRCS(CTh), ${ }^{b}$ David P Jenkins, FRCS(CTh), ${ }^{a}$ Joanna Pepke-Zaba, MD, and John J. Dunning, FRCS(CTh), ${ }^{a}$ Cambridge and Middlesbrough, United Kingdom

$\mathrm{P}$ rimary pulmonary artery angiosarcoma (PAS) is a rare, aggressive, and often fatal tumor of the main pulmonary artery that was first described by Mandelstamm ${ }^{1}$ in 1923. Only around 200 histologically confirmed incidences ${ }^{2}$ of PAS have been documented in the literature to date. The origin of

From Papworth Hospital, Papworth Everard, ${ }^{\mathrm{a}}$ Cambridge, and James Cook University Hospital, ${ }^{\mathrm{b}}$ Middlesbrough, United Kingdom.

Received for publication Oct 30, 2005; accepted for publication Nov 14, 2005.

Address for reprints: Mr Andrew Goodwin, Consultant Cardiothoracic Surgeon, James Cook University Hospital, Middlesbrough, TS4 3BW, United Kingdom (E-mail: andrew.goodwin@stees.nhs.uk).

J Thorac Cardiovasc Surg 2006;131:1410-1

$0022-5223 / \$ 32.00$

Copyright $\odot 2006$ by The American Association for Thoracic Surgery doi:10.1016/j.jtcvs.2005.11.045 these angiosarcomas is still uncertain, although characteristically they arise from pluripotent intimal cells possibly through the malignant development of intimal/subintimal myofibroblasts. ${ }^{3}$ These thoracic sarcomas generally arise from the pulmonary trunk, spreading to the main or proximal pulmonary arteries, with occasional involvement of the pulmonary valve. The diagnosis is clinically difficult to distinguish from chronic thromboembolic pulmonary hypertensive (CTEPH) disease owing to the similarity of symptoms at presentation. We describe our experience in a single institution.

\section{Clinical Summary}

Since 1988 we have treated 9 patients ( 5 female) with PAS whose ages ranging from 26 to 73 years (mean 44 years). Early in the series, 1 patient had a pneumonectomy and another had a heartlung transplant. Since 1999, of 250 patients undergoing pulmonary thromboendarterectomy (PTE), 6 have undergone attempted PTE 


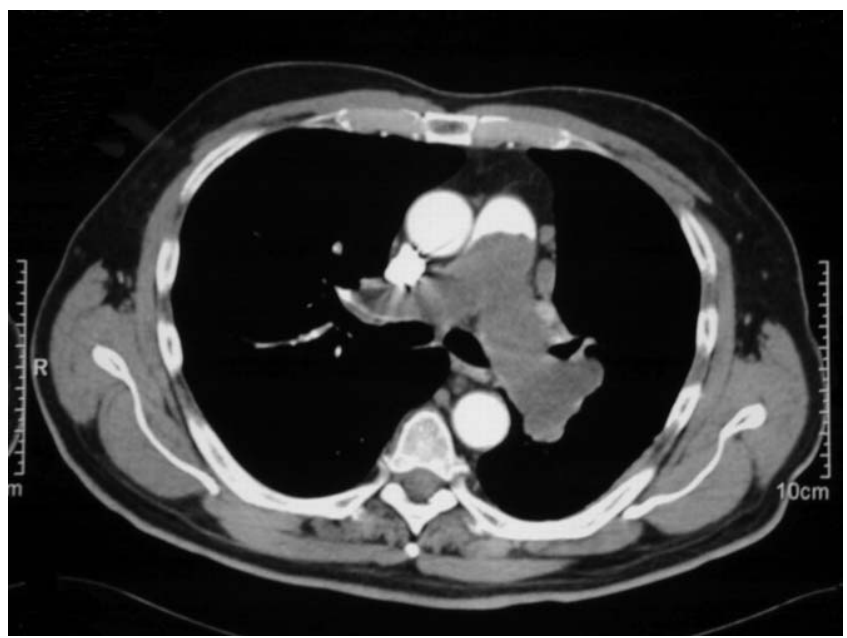

Figure 1. Computed tomographic scan showing central occlusive material within pulmonary trunk, as well as both left and right main pulmonary arteries.

for PAS. One patient was scheduled for surgery but died 1 day preoperatively. A diagnosis of PAS was made post mortem.

All patients were in New York Heart Association class IV preoperatively except for 2 who were in class II. Mean pulmonary artery pressure preoperatively was $82 / 34 \mathrm{~mm} \mathrm{Hg}$ (mean $51 \mathrm{~mm} \mathrm{Hg}$ ), mean cardiac index was 1.9, and pulmonary vascular resistance was 1115 dynes $\cdot \mathrm{s} \cdot \mathrm{cm}^{-5}$. A definitive diagnosis of PAS was not made until during the operation in all cases, although there was a high index of clinical suspicion in the last 4 patients in the series. Factors suggestive of PAS rather than CTEPH were rapid progression of symptoms, absence of a history of deep vein thrombosis, failure of resolution with thrombolysis in acute cases, and central occlusion on computed tomographic imaging, in particular, involvement of the pulmonary valve and pulmonary trunk (Figures 1 and 2). However, these can all occur in CTEPH, making the diagnosis extremely difficult.

In the 6 patients undergoing attempted PTE, surgery was performed under hypothermic $\left(18^{\circ} \mathrm{C}\right)$ cardiopulmonary bypass. There was 1 concomitant pulmonary valve replacement. The mean bypass time was 333 minutes and crossclamp time, 82 minutes. Intermittent circulatory arrest was required in 3 patients (mean 19 minutes).

There were 3 perioperative deaths. The patient receiving a heart-lung transplant died at 145 days of disseminated metastases, possibly exacerbated by immunosuppression. The 3 survivors of PTE are alive 142, 428, and 1298 days after the operation. The patient who had a pneumonectomy has been lost to follow-up.

\section{Discussion}

Because of the difficulty with diagnosis, the most commonly described surgical intervention is PTE, this being the optimal procedure for CTEPH disease. Although unlikely to prove curative in PAS, it does provide the best route to palliation by disobliterating the pulmonary tree and hence relieving the primary cause of

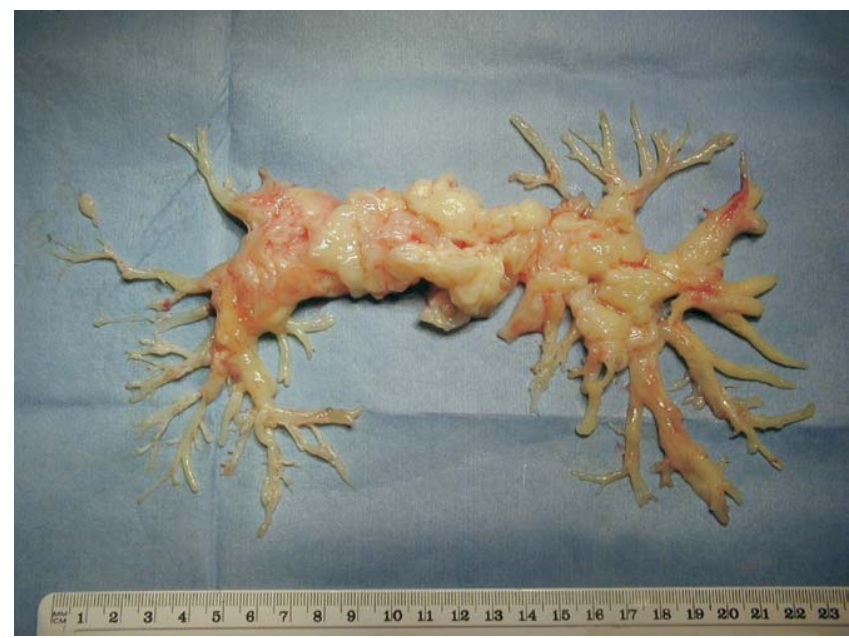

Figure 2. Resected pulmonary artery sarcoma specimen.

symptoms. Studies have also demonstrated that adjuvant chemotherapy or radiotherapy can improve mean survival times by at least 2 - to 3 -fold. ${ }^{4}$

Although initially postulated, pneumonectomy is unlikely to provide adequate clearance of PAS. These tumors generally arise from the pulmonary trunk, extending more distally and occasionally bilaterally; hence, unless combined with further surgery to resect the more central lesion, pneumonectomy alone would be less than ideal. In fact, it may even exacerbate the degree of right heart failure that inevitably accompanies such obstructive lesions.

There is only 1 previously described case of heart-lung transplantation for PAS. ${ }^{5}$ However, as in our case, even this approach did not allow satisfactory eradication of tumor, since after death due to secondary infection at 4 months, autopsy still identified evidence of metastatic disease.

In conclusion, PAS is a rare and aggressive tumor of the pulmonary vasculature, in which diagnostic differentiation from CTEPH may prove difficult and may be delayed owing to the similarity of their characteristic symptoms. Early surgical intervention with possible coadjuvant irradiation or chemotherapy might allow significant palliation and improve quality of life for these patients.

\section{References}

1. Mandelstamm M. Über primäre Neubildungen des Herzens. Virchows Arch Pathol Anat. 1923;245:43-54.

2. Yi CA, Lee KS, Choe YH, Han D, Kwon OJ, Kim S. Computed tomography in pulmonary artery sarcoma: distinguishing features from pulmonary embolic disease. J Comput Assist Tomogr. 2004;28:34-9.

3. Johansson L, Carlen B. Sarcoma of the pulmonary artery: report of four cases with electron microscopic and immunohistochemical examinations, and review of the literature. Virchows Arch. 1994;424:217-24.

4. Head HD, Flam MS, John MJ, Lipnik SS, Slater DL, Stewart RD. Long term palliation of pulmonary artery sarcoma by radical excision and adjuvant therapy. Ann Thorac Surg. 1992;53:332-4.

5. Britton PD. Primary pulmonary artery sarcoma-a report of two cases with a special emphasis on the diagnostic problems. Clin Radiol. 1990;41:92-4. 